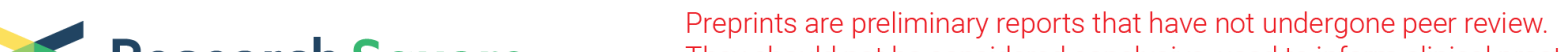 $\begin{array}{ll}\text { Research Square } & \text { They should not be considered conclusive, used to inform clinical practice, } \\ \text { or referenced by the media as validated information. }\end{array}$
}

\section{Reduction in Malaria Burden Following the Introduction of Indoor Residual Spraying in Areas Protected by Long Lasting Insecticidal Nets in Western Kenya, 2016 - 2018}

Diba Dulacha ( $\sim$ diba8088@gmail.com )

Field Epidemiology Training Program https://orcid.org/0000-0002-5549-4664

Vincent Were

CDC Kenya: Centers for Disease Control and Prevention Global Health Kenya

Elvis Oyugi

Field Epidemiology Training Program

Rebecca Kiptui

Kenya MOH: Kenya Ministry of Health

Maurice Owiny

Field Epidemiology Training Program

Waqo Boru

Field Epidemiology Training Program

\section{Zeinab Gura}

Field Epidemiology Training Program

Robert T. Perry

CDC Kenya: Centers for Disease Control and Prevention Global Health Kenya

\section{Research}

Keywords: Malaria, incidence, Kenya,

Posted Date: October 5th, 2021

DOl: https://doi.org/10.21203/rs.3.rs-924146/v1

License: (-) (i) This work is licensed under a Creative Commons Attribution 4.0 International License. Read Full License 


\section{Abstract}

Background: Long-lasting insecticidal nets (LLINs) and indoor residual spraying (IRS) are the main malaria vector control measures. Kenya has employed multiple approaches, including free mass net distribution campaigns, for distributing LLINs to the community that resulted in increased household ownership of one or more nets from 44\% in 2010 to $63 \%$ in 2015. Migori and Homa Bay Counties are among the malaria endemic counties in Western Kenya that benefitted from three free mass net distribution campaigns between 2012 and 2018.. Widespread pyrethroid resistance among the primary vectors in Western Kenya has necessitated the re-introduction of IRS using an organophosphate insecticide, pirimiphos-methyl (Actellic $\circledast 300 \mathrm{CS}$ ), as part of a strategy to manage insecticide-resistance. Evaluation of the effectiveness of the combined use of non-pyrethroid IRS and LLINs have yielded varied results. We aimed to evaluate malaria indicators before and after the introduction of IRS in a high malaria transmission area compared with an adjacent area where IRS was not introduced until one year later to estimate the effect of the intervention in an area with pyrethroid resistance.

Methods: We reviewed records ( $\mathrm{MoH} 405 \mathrm{~A}, 405 \mathrm{~B}$, and 706) and tallied monthly aggregate of outpatient department (OPD) attendance, suspected malaria cases, those tested for malaria and those testing positive for malaria at two health facilities, one from Nyatike, an intervention sub-county, and one from Suba, a comparison sub-county, both located in Western Kenya, from February 1, 2016, through March 31, 2018. The first round of IRS was conducted in February - March 2017 in Nyatike sub-county and the second round one year later in both Nyatike and Suba sub-counties while the mass distribution of LLINs has been conducted in both locations. We performed a descriptive analysis and estimated the effect of the interventions and temporal changes of malaria indicators using Poisson regression for a period before and after implementation of the first round of IRS.

Results: A higher reduction in the intervention area in total OPD, the proportion of OPD visits due to suspected malaria, testing positivity rate and annual malaria incidences except for the total OPD visits among the under 5 children where $59 \%$ decrease was observed in the comparison area while $33 \%$ decrease was observed in the intervention area (net change $-27 \%, \mathrm{P}<0.001$ ). The percentage decline in annual malaria incidence observed in the intervention area was more than twice the observed percentage decline in the comparison area across all the age groups. A marked decline in the monthly testing positivity rate (TPR) was noticed in the intervention area, while no major changes were observed in the comparison area upon introduction of the non-pyrethroid IRS in the intervention area. The monthly TPR reduced from $46 \%$ in February 2016 (start of review period) to 11\% in February 2018 (end of review period), representing a 76\% absolute decrease in TPR among all ages ( $R R=0.24,95 \% \mathrm{Cl} 0.12-0.46)$. In the comparison area, TPR was 16\% in both February 2016 and February 2018 (RR=1.0, 95\% Cl 0.52-2.09). A month-by-month comparison revealed that the TPR in Year 2 remained lower than in Year 1 in the intervention area for most of the one year after the introduction of the IRS.

Conclusions: Our findings demonstrated a reduced malaria burden among population protected by both non-pyrethroid IRS and LLINs implying a possible additional benefit afforded by the combined intervention in malaria endemic zone. 


\section{Introduction}

Malaria, caused by infection with parasites of the genus Plasmodium, is a global public health problem with an estimated 228 million cases and 405,000 deaths reported in 2018 [1]. The prevalence of malaria found through screening during household surveys varies widely across different malaria epidemiological zones in Kenya. In the malaria-endemic counties in Western Kenya, the prevalence was estimated to be $27 \%$ in children under five years of age in 2015 [2]. Malaria and its complications, like anemia, were identified as the most common causes of childhood mortality in Western Kenya between 2003 and 2009 [3].

Long-lasting insecticidal nets (LLINs) and indoor residual spraying (IRS) are the main vector control measures recommended by the WHO [4]. Insecticide-treated nets (ITNs) are associated with a significant reduction in malaria incidence rates of $50 \%$ and malaria mortality rates of $55 \%$ among children under five years of age in Sub-Saharan Africa [5], [6]. Various approaches have been used in Kenya to distribute pyrethroid-impregnated nets, including free mass net distribution campaigns, designed to reach universal coverage, and routine distribution, targeting pregnant women and children under one year of age in endemic and epidemic-prone areas. These efforts have led to an improvement in the proportion of households nationwide with one or more nets increasing from 44\% in 2010 to $63 \%$ in 2015 [7]. Small-area analyses combining Demographic Health Survey (DHS) 2014 and Kenya Malaria Indicator Survey (KMIS) 2015 estimated that the proportion of households that attained with universal coverage with LLINs, defined as one LLIN for every two people in the household, was $32 \%$ in Migori County where the intervention area (Nyatike sub-county) is located and $39 \%$ in Homa Bay County where the comparison area (Suba subcounty) is located [8]. These adjoining counties, Migori and Homa Bay, are located in the malaria-endemic zone of Western Kenya around Lake Victoria, where there is intense malaria transmission throughout the year with annual entomological inoculation rates of 30-100 [16].

IRS has also been demonstrated to reduce morbidity and mortality, although data on the effectiveness of the IRS are not as comprehensive as those on insecticide-treated nets (ITNs) [7]. In Kenya, pyrethroid-based IRS activities were stopped in 2013 when widespread pyrethroid resistance was reported among the primary vectors [9], [10]. IRS was re-introduced in February 2017 in Migori County using an organophosphate insecticide, pirimiphos-methyl (Actellic $\circledast 300 \mathrm{CS}$ ), as part of a strategy to manage insecticide-resistance [11]. WHO recommends the use of a different class of insecticide for IRS from one used in nets to reduce the development of resistance to and protect pyrethroids, for instance, the use of carbamate or organophosphate insecticide for IRS in areas where pyrethroid-impregnated LLINs are distributed [10], [11].

Kenya has conducted three free mass net distribution campaigns; in 2011-2012, 2014-2015, and 20172018. During the 2017-2018 campaign, nets were distributed in Migori and Homa Bay counties in June 2017. In addition, free LLINs are given to pregnant women attending their first antenatal clinic and to children under one year of age attending their first visit to a vaccination clinic. The proportion of the population who reported sleeping under an LLIN was $51 \%$ in Migori County and $53 \%$ in Homa Bay County (8). The non-pyrethroid IRS campaign in 2017 was conducted using an organophosphate, pirimiphos- 
methyl (Actellic $\circledast 300 \mathrm{CS}$ ) in six of the eight sub-counties of Migori in February and March 2017. A household survey was done one to two months after the campaign estimated that $83 \%$ of eligible structures were sprayed during the first round of the IRS [17]. The second round of non-pyrethroid IRS using the same insecticide was done in the same six sub-counties of Migori County and in all sub-counties of Homa Bay County in February and March 2018.

The combined use of LLINs and IRS has been shown in field studies to have a more significant impact than either of the interventions used alone [12][13]. A systematic review of studies examining the impact of IRS on key malariological parameters found enhanced protection among populations using both ITNs and IRS compared to IRS alone [14]. However, other studies have not shown any additional advantage with the combination of two vector control interventions [15]. The recent expansion of the IRS has led to the need for epidemiological data describing its impact in malaria-endemic areas. In order to better understand the added benefit of IRS; we compared the malaria burden at two health centers, one in an area where IRS was conducted and one in an area where it was not conducted.

\section{Methods And Materials}

\section{Study Design}

This study was a quasi-experimental design utilizing a retrospective review of medical and laboratory records for pre-intervention and post-intervention periods to compare changes in malaria indicators between intervention and comparison areas. The malaria indicators of interest were the number of confirmed outpatient malaria cases per 1000 persons per month, the proportion of suspected malaria among all cases seen in the Outpatient Department (OPD), the testing rate, and the test positivity rate. The intervention was the combination of non-pyrethroid IRS (the first round) and LLINs, which took place in the Nyatike sub-County (intervention area) in Migori County in 2017. The comparison area (Suba sub-County) received LLINs alone when the intervention area received non-pyrethroid IRS (first round) in addition to the LLINs. The comparison area was chosen based on geographical proximity and similarity of climatic conditions to the intervention area. The pre-intervention period (year 1) was from February 1, 2016, to January 31, 2017, and the post-intervention period (year 2) was from April 1, 2017, to March 31, 2018. One facility from the Nyatike sub-county where the catchment population received the first round of nonpyrethroid IRS was selected as the intervention site, and another facility from Suba sub-county where the population did not receive the IRS during the first-round campaign was selected as the comparison site.

\section{Study Site And Vector Control Interventions}

The two health facilities were Karungu Sub-County Hospital in Nyatike sub-county in Migori County, where the combination of non-pyrethroid IRS (first round) and LLINs took place and Suba Sub-County Hospital in Suba sub-county in Homa Bay County where the first round of non-pyrethroid IRS campaign was not done. 
Malaria is perennial in these counties, with two major peaks that usually follow the two annual rainy seasons of March/April/May and September/October/November [16].

\section{Data Collection}

We reviewed outpatient ( $\mathrm{MoH} 405 \mathrm{~A}, 405 \mathrm{~B}$ ) and laboratory (MoH 706) registers and tallied monthly aggregate numbers of all outpatient department (OPD) visits, suspected malaria cases, patients tested for malaria with either microscopy or rapid diagnostic test (RDT), and patients who tested positive for malaria, disaggregated into two age categories - younger than five years old and those aged five years and above. The OPD registers included information on each person attending the OPD, clinical diagnosis, tests that were requested, and the treatment given. The laboratory registers provide for each person tested, tests performed, and the results. Data review covered one year before the first round of IRS (from February 1 , 2016, through January 31, 2017) and one year after the first round of IRS (from April 1, 2017, through March 31, 2018) for both facilities.

\section{Data Management And Analysis}

We entered data into MS Excel for cleaning and analyzed the data using STATA (STATA Corp., College Station, TX, USA). For the months with missing variables, we imputed using the averaging method where the missing values were generated using averages of the values of the preceding month and the month that follows the month with a missing value.

Annual malaria incidence was the number of confirmed cases per 1,000 populations using the mid-year estimated catchment population of each facility. The test positivity rate was the ratio of slides or RDT tests done that tested positive for malaria over the number of patients tested by microscopy or RDT. We also calculated the proportion of all outpatient department (OPD) visits with a diagnosis of suspected malaria as the number of patients diagnosed with suspected malaria divided by the total number of all OPD visits.

We created two categorical variables to use in regression models, one for spray status, to allow comparisons between the intervention area and the comparison area, and another for the time, to allow comparisons between the period before IRS (February 1, 2016, to January 31, 2017), labeled as "Year 1", and the period after IRS in Nyatike Sub-county (April 1, 2017, to March 31, 2018), labeled as "Year 2". We used the time variable to estimate the differences in malaria indicators between Year 1 and Year 2 and the spray status variable to compare changes in malaria indicators between the facility in the area where the first round of IRS was done and the facility in the area where it was not done. We applied the difference-indifferences (DID) approach [17], [18], to estimate the difference between Year 1 and Year 2 for the proportion of OPD visits due to suspected malaria and testing positivity rates, and differences between percentage change for total OPD visits and annual malaria incidences. We used a mixed-effect Poisson regression model to measure the effect of the intervention on the malaria indicators where the coefficient of the interaction term between spray status variable and period of study (year 1 vs. year 2) represented the net of effect of IRS. The comparison of monthly test positivity rates was made by calculating the relative 
rate (RR) using Poisson regression to assess the presence of significant differences in temporal trends of the indicators over the period of interest. We calculated the RR of monthly testing positivity rates (TPRs) without any adjustments for other variables for month-to-month comparison. For the Poisson regression model, the relative rate $(\mathrm{RR})$ of $<1$ was considered protective, and the $\mathrm{p}$-value of $<0.05$ statistically significant.

\section{Results}

The combination of the non-pyrethroid IRS and LLINs in the intervention was associated with higher percentage decrease for all indicators except the OPD visits among the under 5 children where $59 \%$ decrease was observed in comparison area while 33\% decrease was observed in the intervention area (net change $-27 \%, P<0.001)$. A negative percentage change $(-4 \%)$ in the total OPD visits was observed among the 5-and-over population as a slight increase in total OPD visits was observed in Year 2.

The greatest net decline in the proportion of OPD attendance attributed to suspected malaria cases and TPR was observed among the under-five children (-27\% intervention area vs $-7.3 \%$ comparison area, net change $-20 \%, P<0.001)$ and among the five-and-over population ( $-34 \%$ intervention area vs. $-1.8 \%$ comparison area, net change $-23 \%, \mathrm{P}<0.001$ ) respectively.

The percentage decline in malaria incidences observed in the intervention area was more than twice the observed percentage decline in the comparison area across all the age groups (Table 1). The missing records for the number of malaria tests performed and the number of confirmed malaria cases for February 2016, February 2017, and December 2017 were computed for the comparison area (Table 1). 
Table 1

Changes in annual malaria indicators in the intervention area and comparison area before and after the introduction of the first round of IRS, 2016-2017

\begin{tabular}{|c|c|c|c|c|c|c|c|c|}
\hline \multirow[t]{2}{*}{$\begin{array}{l}\text { Malaria } \\
\text { indicators }\end{array}$} & \multicolumn{3}{|c|}{$\begin{array}{l}\text { Intervention area (IRS + } \\
\text { LLIN) }\end{array}$} & \multicolumn{3}{|c|}{$\begin{array}{l}\text { Comparison area (LLIN } \\
\text { alone) }\end{array}$} & \multicolumn{2}{|c|}{ Net change } \\
\hline & Year 1 & $\begin{array}{l}\text { Year } \\
2\end{array}$ & $\begin{array}{l}\text { Change } \\
\text { (A) }\end{array}$ & Year 1 & Year 2 & $\begin{array}{l}\text { Change } \\
\text { (B) }\end{array}$ & $A-B$ & $\begin{array}{l}\mathrm{P} \text { - } \\
\text { value }\end{array}$ \\
\hline Total OPD visits* & & & $\begin{array}{l}\% \\
\text { change }\end{array}$ & & & $\begin{array}{l}\% \\
\text { change }\end{array}$ & $\begin{array}{l}\text { Int- } \\
\text { comp }\end{array}$ & \\
\hline All ages & 12460 & 6948 & $44 \%$ & 19823 & 15160 & $24 \%$ & $21 \%$ & $\begin{array}{l}< \\
0.001\end{array}$ \\
\hline$<5$ & 2741 & 1848 & $33 \%$ & 8621 & 3502 & $59 \%$ & $-27 \%$ & $\dot{0.001}$ \\
\hline$\geq 5$ & 9719 & 5100 & $48 \%$ & 11202 & 11658 & $-4 \%$ & $52 \%$ & $\begin{array}{l}< \\
0.001\end{array}$ \\
\hline $\begin{array}{l}\text { Suspected } \\
\text { malaria casest } \\
\text { (\% of OPD visits) }\end{array}$ & & & Diff \% & & & Diff \% & DiD & \\
\hline All ages & $\begin{array}{l}3966 \\
(32)\end{array}$ & $\begin{array}{l}746 \\
(11)\end{array}$ & -21 & $\begin{array}{l}7284 \\
(37)\end{array}$ & $\begin{array}{l}4780 \\
(32)\end{array}$ & -5.2 & -16 & $\begin{array}{l}< \\
0.001\end{array}$ \\
\hline$<5$ & $\begin{array}{l}1026 \\
(37)\end{array}$ & $\begin{array}{l}184 \\
(10)\end{array}$ & -27 & $\begin{array}{l}2607 \\
(30)\end{array}$ & $\begin{array}{l}801 \\
(23)\end{array}$ & -7.3 & -20 & $\begin{array}{l}< \\
0.001\end{array}$ \\
\hline$\geq 5$ & $\begin{array}{l}2940 \\
(30)\end{array}$ & $\begin{array}{l}562 \\
(11)\end{array}$ & -19 & $\begin{array}{l}4677 \\
(42)\end{array}$ & $\begin{array}{l}3979 \\
(34)\end{array}$ & -7.7 & -12 & $\dot{0.001}$ \\
\hline $\begin{array}{l}\text { Tested positive } \neq \\
\text { (\% of tested) }\end{array}$ & & & Diff \% & & & Diff \% & DiD & \\
\hline All ages & $\begin{array}{l}3847 \\
(39)\end{array}$ & $\begin{array}{l}436 \\
(14)\end{array}$ & -25 & $\begin{array}{l}2929 \\
(19)\end{array}$ & $\begin{array}{l}1147 \\
(16)\end{array}$ & -3.4 & -21 & $<0.001$ \\
\hline$<5$ & $\begin{array}{l}1144 \\
(27)\end{array}$ & $\begin{array}{l}172 \\
(16)\end{array}$ & -11 & $\begin{array}{l}1331 \\
(23)\end{array}$ & $\begin{array}{l}469 \\
(17)\end{array}$ & -5.6 & -6 & 0.006 \\
\hline$\geq 5$ & $\begin{array}{l}2703 \\
(47)\end{array}$ & $\begin{array}{l}264 \\
(13)\end{array}$ & -34 & $\begin{array}{l}1598 \\
(17)\end{array}$ & $\begin{array}{l}678 \\
(15)\end{array}$ & -1.8 & -32 & $\begin{array}{l}<.001 \\
0.001\end{array}$ \\
\hline
\end{tabular}

OPD = Outpatient department; Int-change in intervention area; Comp-change in comparison area; DiDdifference-in-differences

* All outpatient visits as recorded in the OPD registers

† Proportions of all outpatient visits contributed by suspected malaria cases

₹ Number of samples tested positive for malaria divided by total number of malaria tests done

$\S$ Annual malaria incidence rates using the mid-year population estimates for the two facilities as the denominators and expressed as per 1,000 populations 


\begin{tabular}{|c|c|c|c|c|c|c|c|c|}
\hline \multirow[t]{2}{*}{$\begin{array}{l}\text { Malaria } \\
\text { indicators }\end{array}$} & \multicolumn{3}{|c|}{$\begin{array}{l}\text { Intervention area (IRS + } \\
\text { LLIN) }\end{array}$} & \multicolumn{3}{|c|}{$\begin{array}{l}\text { Comparison area (LLIN } \\
\text { alone) }\end{array}$} & \multicolumn{2}{|c|}{ Net change } \\
\hline & Year 1 & $\begin{array}{l}\text { Year } \\
2\end{array}$ & $\begin{array}{l}\text { Change } \\
\text { (A) }\end{array}$ & Year 1 & Year 2 & $\begin{array}{l}\text { Change } \\
\text { (B) }\end{array}$ & A-B & $\begin{array}{l}\mathrm{P} \text { - } \\
\text { value }\end{array}$ \\
\hline $\begin{array}{l}\text { Malaria } \\
\text { incidence/1000§ }\end{array}$ & & & $\begin{array}{l}\% \\
\text { change }\end{array}$ & & & $\begin{array}{l}\% \\
\text { change }\end{array}$ & $\begin{array}{l}\text { Int- } \\
\text { comp }\end{array}$ & \\
\hline All ages & 360 & 38 & $89 \%$ & 131 & 78 & $40 \%$ & $49 \%$ & $\begin{array}{l}< \\
0.001\end{array}$ \\
\hline$<5$ & 552 & 78 & $86 \%$ & 360 & 194 & $46 \%$ & $40 \%$ & $\begin{array}{l}< \\
0.001\end{array}$ \\
\hline$\geq 5$ & 314 & 29 & $91 \%$ & 85 & 55 & $35 \%$ & $56 \%$ & $<.001$ \\
\hline \multicolumn{9}{|c|}{$\begin{array}{l}\text { OPD = Outpatient department; Int-change in intervention area; Comp-change in comparison area; DiD- } \\
\text { difference-in-differences }\end{array}$} \\
\hline \multicolumn{9}{|c|}{ * All outpatient visits as recorded in the OPD registers } \\
\hline \multicolumn{9}{|c|}{ † Proportions of all outpatient visits contributed by suspected malaria cases } \\
\hline \multicolumn{9}{|c|}{ ‡ Number of samples tested positive for malaria divided by total number of malaria tests done } \\
\hline
\end{tabular}

Before the introduction of the non-pyrethroid IRS in the intervention area, overall monthly TPR was higher in the intervention area than in the comparison area. A marked decline in the monthly TPR was observed in the intervention area while no major changes are observed in the comparison area upon introduction of the non-pyrethroid IRS in the intervention area. The monthly TPR reduced from 46\% in February 2016 (start of review period) to 11\% in February 2018 (end of review period), representing a 76\% absolute decrease in TPR among all ages ( $\mathrm{RR}=0.24,95 \% \mathrm{Cl} 0.12-0.46$ ). In the comparison area, TPR was $16 \%$ in both February 2016 and February 2018 ( $R R=1.0,95 \% \mathrm{Cl} 0.52-2.09)$. A month-by-month comparison revealed that the TPR in Year 2 remained lower than in Year 1 in the intervention area for most of the one year after the introduction of the IRS. In comparison area, the overall TPR remained relatively stable in Year 1 and Year 2. An unexplained spike was observed in the comparison area in March 2018 in Year 2 (Fig. 2).

\section{Discussion}

Our retrospective review of medical records found a marked reduction in malaria incidence, TPR, and proportion of OPD visits due to suspected malaria in the catchment area of a hospital in a sub-county where IRS was done, compared to the catchment area of a hospital in a sub-county where IRS was not done. Both areas had moderate rates of LLIN possession. The high malaria transmission seasons in Year 1 and Year 2 were included in the review period and the comparison for key malariological indicators was done between two full calendar years. Our findings suggest that adding IRS with a non-pyrethroid 
insecticide to LLINs impregnated with pyrethroid insecticides is effective in further reducing the malaria burden in an area of widespread pyrethroid resistance. These findings add to a growing body of evidence showing additional benefits afforded by a combination of IRS and LLINs using different insecticides in malaria-endemic areas and the significance of managing insecticide resistance.

A similar study utilizing enhanced routine surveillance data at an outpatient facility in Apac District in Uganda demonstrated a dramatic decline in malaria morbidity after initiation of IRS with bendiocarb and resurgence in malaria cases three months after discontinuation of IRS [19]. In addition, a pre-post comparison study done in Tororo District in Uganda district using secondary data from health facilities for the period between 2013 and 2015 noted a significant reduction in the incidence of malaria among < 5year-old children from 130 to 100 cases per in 2014 when LLINs were used alone and a further significant decline to 45 cases per 1000 in 2015 when IRS was combined with LLINs [20]. The presence of high-level pyrethroid resistance among the primary vectors in multiple parts of Uganda, including both Apac and Tororo, has been demonstrated [21][22]. A non-randomized prospective study in western Kenya comparing the impact of combined use of ITNs and IRS against the use of ITNs alone also showed a lower incidence of $P$. falciparum (18 per 100 persons-years at risk) among the group with both ITNs and IRS than the group with ITNs only (44 per 100 persons-year at risk) with an adjusted rate ratio of 0.41 (95\% $\mathrm{Cl} 0.31-0.56)$ [13]. Another study done in 2008-2009 in Rachuonyo and Nyando areas in western Kenya, where prevalence was measured by repeated household surveys of randomly-selected households visited on a monthly basis, showed lower malaria prevalence in a district with pyrethroid IRS (lambdacyhalothrin in year 1 and, alphacypermethrin in year 2 ) compared with a neighboring district where only ITNs were provided (6.4\% vs $16.7 \%, \mathrm{OR}=0.36,95 \% \mathrm{Cl} 0.22-0.59$ ) [23]. A review of data from six countries examining the effect of combining IRS and LLINs found mixed results, with possibly additional benefits from the combination in a setting with low-medium LLIN usage [24]. IRS, implemented targeting high coverage of more than $85 \%$ of eligible structures, is associated with a rapid reduction in vector population and affords protection to the community members not sleeping under mosquito nets and additional protection to those who sleep under LLINs/ITNs, explaining the more significant reduction among those in houses covered by IRS who are also using LLINs. While LLINs can potentially have a similar effect on malaria vector populations its efficacy is affected by failure to achieve the universal coverage despite multiple mosquito net distributions campaigns and the widespread pyrethroid resistance.

Other studies have shown protective effects of IRS and ITNS used together but failed to demonstrate any difference between the use of the combination and either intervention alone. Protopopoff and colleagues found in Burundi that despite reduced vector densities inside houses secondary to use of ITNs and IRS, the overall transmission of malaria was not significantly reduced relative to when either of the two methods was used alone. However, this result may reflect more the choice of the control site [25]. In rural Gambia with moderate seasonal malaria transmission and high LLINs coverage, the addition of IRS using DDT as the insecticide did not result in a significant reduction in the levels of clinical malaria compared to the control group where LLINs were deployed alone. The failure to observe a significant reduction in malaria incidences in this study is attributed to the high LLINs coverage, of $83-95 \%$, among the children in the 
cohort whose households received LLINs as part of the study that led to a reduced number of bloodfeeding mosquitoes settling on the walls [26].

Our study had some limitations; gaps in the quality of the routine facility data may have affected our analysis. The ratio of cases tested in the laboratory to cases seen in the outpatient department was consistently higher than one, likely a result of our inability to restrict the data collection to only outpatients and exclude cases coming from other parts of the hospital like the antenatal clinic or inpatient wards. In addition, some RDTs done outside the laboratory or by non-laboratory personnel in different parts of the facilities may not have been recorded in the laboratory registers. We calculated incidence based on the health facility catchment population, but clients may have come from areas outside the catchment area as the selected facilities are the major referral health facilities in the two sub-counties. The limited number of health facilities included for data collection limits our ability to generalize our findings to the whole subcounty or county. The results are also subject to selection bias for testing and the accuracy of laboratory testing. Further, the inability to exclude the tests done on the inpatient cases meant that a certain percentage of our positive cases could have been the admitted cases. The other limitation was the lack of data on climatic and environmental factors that affect malaria risk and transmission. However, these issues could have affected both the intervention and comparison sites, thus reducing the effect of these biases on the general findings.

For at least up to the last malaria indicator survey in 2015, Suba and Nyatike had inadequate coverage with LLINs - and since one needs to possess a net to use it, these areas also had reduced rates of net use. Pyrethroid resistance in mosquito vectors may have blunted the effectiveness of pyrethroid-based LLINs. This analysis showed that adding IRS with a non-pyrethroid insecticide in Nyatike seemed to reduce the incidence, compared to no real change in Suba, at least at the sub-county hospital OPD. Expansion of IRS to other malaria-endemic counties, along with considering the use of newer nets to achieve universal coverage, could reduce the malaria burden further.

\section{Declarations}

\section{Acknowledgment}

We acknowledge Migori and Homa Bay counties and their staff for their cooperation and assistance during data collection. We also acknowledge the US Centers for Disease Control and Prevention (CDC), Kenya FELTP, and Moi University for their financial and technical support.

Disclaimer: The findings and conclusions in this report are those of the author(s) and do not necessarily represent the official position of the funding agencies.

\section{Authors' contributions}

DD, AO, RTP, RK, WB, ZG, EO, MO designed the study, the data collection tools, and the analysis plan while DD collected the data and performed data cleaning and sorting. DD, RTP, and VW analyzed the data while DD, RTP, AO, RK, WB, ZG, EO, MO prepared, and reviewed the manuscript. 


\section{Funding}

This work was funded by Kenya Field Epidemiology Training Program with support from the US President's Malaria Initiative (PMI) and Centers for Disease Control and Prevention (CDC).

\section{Availability of data and materials}

The dataset used for this analysis is available from the corresponding author when required.

\section{Ethical approvals and consent to participate}

\section{Ethical Consideration}

Moi University Institution for Research and Ethics Committee (IREC) approved this study (Approval Number: 0002048), and the Health Departments of Migori and Homa Bay Counties gave consent to access the health facilities and the records. The variables collected were monthly summaries, and the data collected did not include patients' names or any other direct identifiers. The study underwent human subject review at the U.S. Centers for Disease Control and Prevention and was approved as a program evaluation activity that does not require human subject research review.

\section{Consent for publication}

Not applicable

\section{Competing interests}

The authors declare that they have no competing interests.

\section{References}

1. WHO. "World malaria report 2019," 2019.

2. MoH, "Kenya malaria indicator survey," 2015.

3. Hamel MJ, et al. A reversal in reductions of child mortality in western Kenya, 2003-2009. Am J Trop Med Hyg. 2011;85(4):597-605.

4. WHO. "Indoor residual spraying: an operational manual for indoor residual spraying (IRS) for malaria transmission control and elimination," no. 2015, 2015.

5. Eisele TP, Larsen D, Steketee RW. Protective efficacy of interventions for preventing malaria mortality in children in Plasmodium falciparum endemic areas. Int J Epidemiol. 2010;39 Suppl 1:i88-101.

6. Lengeler C. "Insecticide-treated bed nets and curtains for preventing malaria," in Cochrane Database Syst Rev, 2004.

7. Pluess B, Tanser FC, Lengeler C, Sharp B. "Indoor residual spraying for preventing malaria," in Cochrane Database Syst Rev, 2010.

8. Noor A. "The epidemiology and control profile of malaria in Kenya," 2016. 
9. Chen H, Githeko AK, Githure JI, Mutunga J, Zhou G, Yan G, "Monooxygenase levels and knockdown resistance $(\mathrm{kdr})$ allele frequencies in Anopheles gambiae and Anopheles arabiensis in Kenya.," J. Med. Entomol., vol. 45, no. 2, pp. 242-50, Mar. 2008.

10. Kawada $\mathrm{H}$, et al. Multimodal Pyrethroid Resistance in Malaria Vectors, Anopheles gambiae s.s., Anopheles arabiensis, and Anopheles funestus s.s. in Western Kenya. PLoS One. Aug. 2011;6(8):e., ",', , 22574.

11. MOH. "Insecticide Resistance Management Strategy 2015-2018," 2015.

12. Kleinschmidt I, et al. Combining indoor residual spraying and insecticide-treated net interventions. Am J Trop Med Hyg. 2009;81(3):519-24.

13. Hamel MJ, et al. The combination of indoor residual spraying and insecticide-treated nets provides added protection against malaria compared with insecticide-treated nets alone. Am J Trop Med Hyg. 2011;85(6):1080-6.

14. Pluess B, Tanser FC, Lengeler C, Sharp BL. "Indoor residual spraying for preventing malaria," Cochrane Libr., 2010.

15. Nyarango PM, et al., "A steep decline of malaria morbidity and mortality trends in Eritrea between 2000 and 2004: the effect of combination of control methods," Malar J, vol. 5, 2006.

16. MOH. “Kenya Malaria Strategy 2009-2018 (Revised 2014)," 2014.

17. Gertler PJ, Martinez S, Premand P, Rawlings LB, Vermeersch CMJ. Impact evaluation in practice. The World Bank; 2016.

18. Saeed S, Moodie EEM, Strumpf EC, Klein MB. Evaluating the impact of health policies: using a difference-in-differences approach. Int J Public Health. 2019;64(4):637-42.

19. Raouf $S$, et al. Resurgence of Malaria Following Discontinuation of Indoor Residual Spraying of Insecticide in an Area of Uganda With Previously High-Transmission Intensity. Clin Infect Dis An Off Publ Infect Dis Soc Am. 2017;65(3):453-60.

20. Oguttu DW, et al. Rapid reduction of malaria following introduction of vector control interventions in Tororo District, Uganda: a descriptive study. Malar J. 2017;16(1):227.

21. Okia M, et al. Insecticide resistance status of the malaria mosquitoes: Anopheles gambiae and Anopheles funestus in eastern and northern Uganda. Malar J. 2018;17(1):157.

22. Steinhardt LC, et al. The effect of indoor residual spraying on malaria and anemia in a hightransmission area of northern Uganda. Am J Trop Med Hyg. 2013;88(5):855-61.

23. Gimnig JE, et al. The Effect of Indoor Residual Spraying on the Prevalence of Malaria Parasite Infection, Clinical Malaria and Anemia in an Area of Perennial Transmission and Moderate Coverage of Insecticide Treated Nets in Western Kenya. PLoS One. 2016;11(1):e0145282.

24. Kleinschmidt I, et al., "Implications of insecticide resistance for malaria vector control with long-lasting insecticidal nets: a WHO-coordinated, prospective, international, observational cohort study," Lancet Infect. Dis., vol. 18, no. 6, pp. 640-649, Jun. 2018.

25. Protopopoff N, et al., "Spatial targeted vector control in the highlands of Burundi and its impact on malaria transmission," Malar J, vol. 6, 2007. 
26. Pinder $\mathrm{M}$, et al. Efficacy of indoor residual spraying with dichlorodiphenyltrichloroethane against malaria in Gambian communities with high usage of long-lasting insecticidal mosquito nets: a clusterrandomised controlled trial. Lancet. 2015;385(9976):1436-46.

\section{Figures}

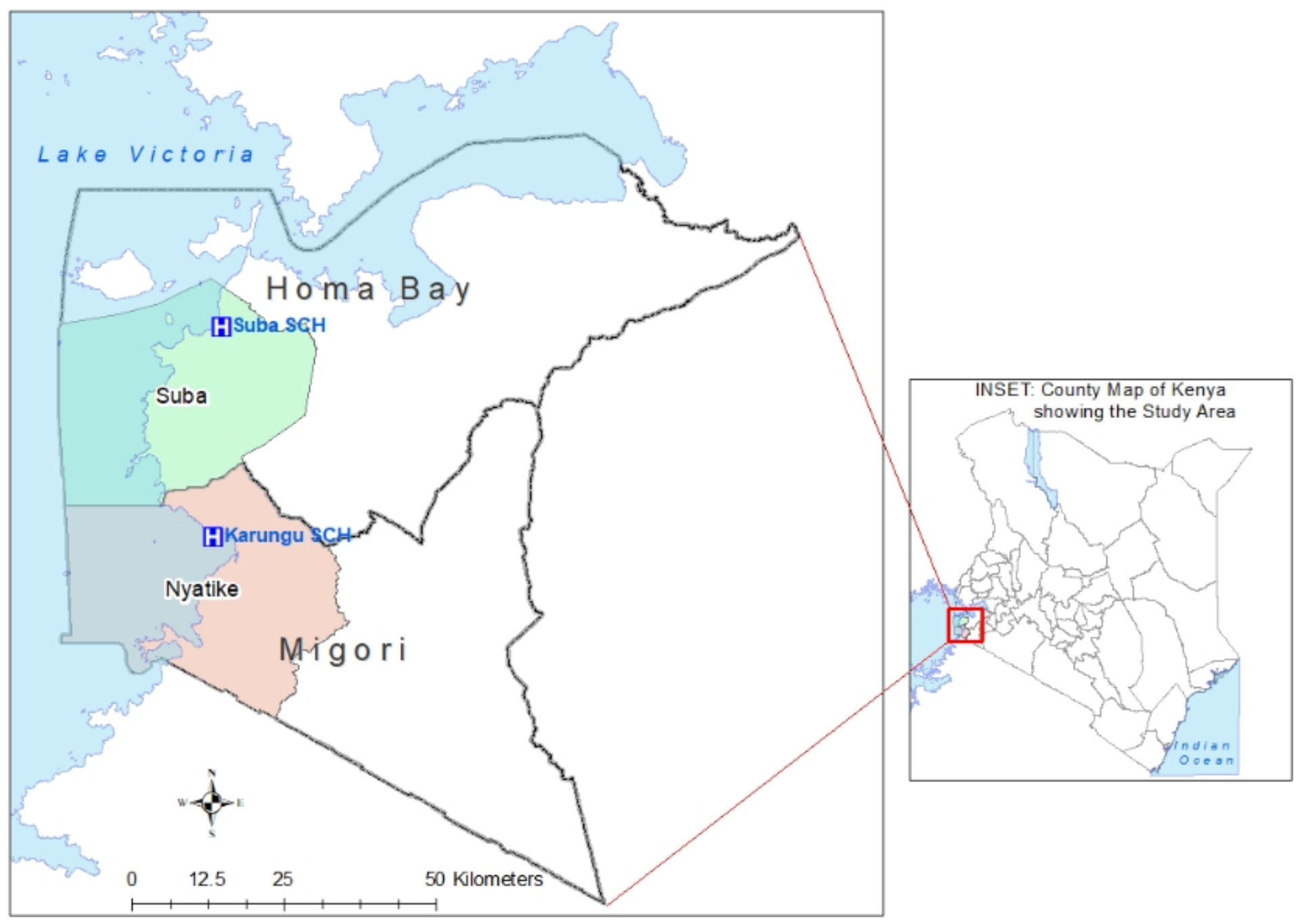

Figure 1

A map of the intervention area (Nyatike Sub-county) and the comparison area (Suba Sub-county) in Kenya, 2018 


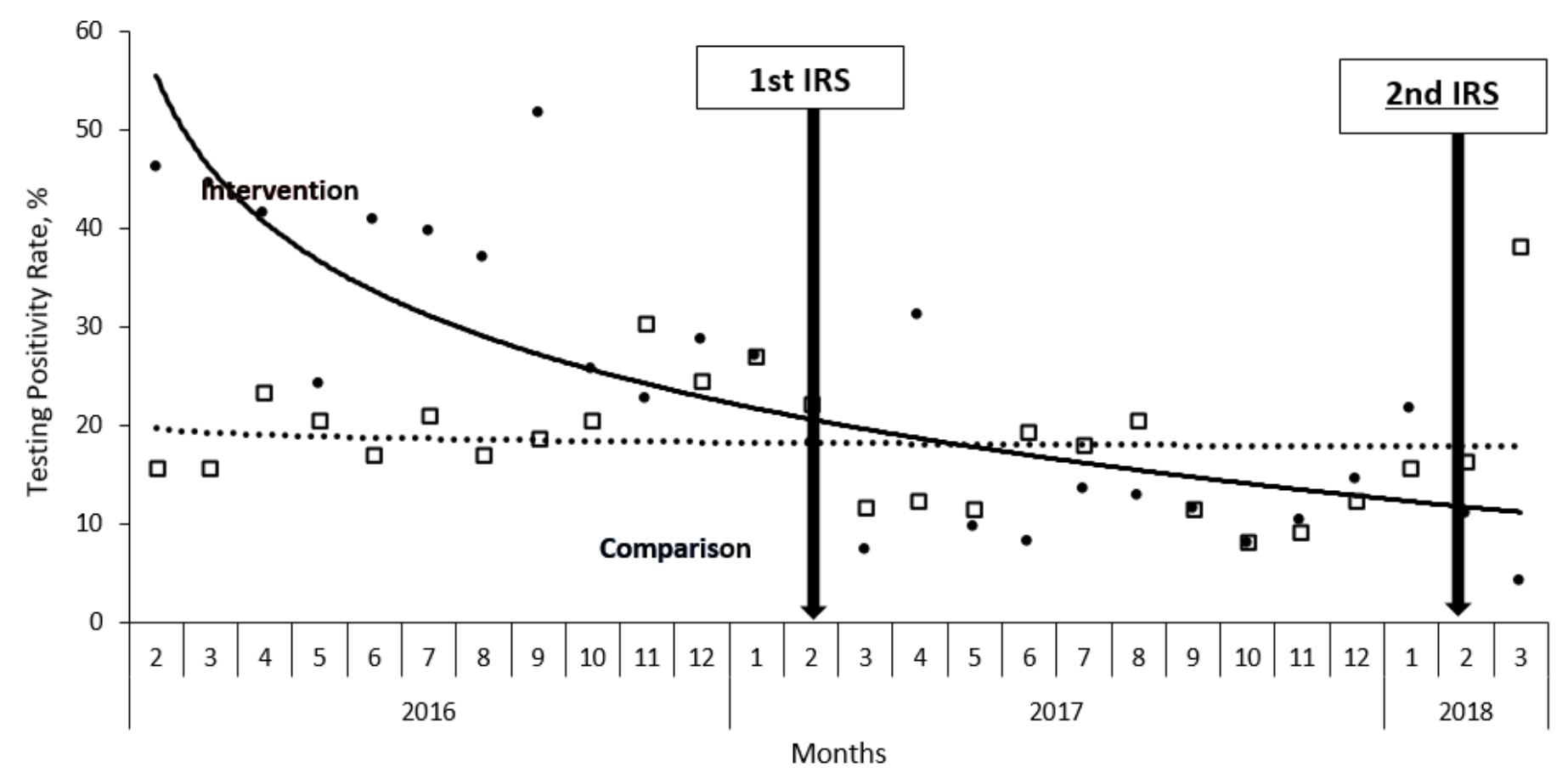

- Intervention $\mathrm{a}$ Control — Log. (Intervention) $\cdots \cdots$ Log. (Control)

Figure 2

Trends of monthly malaria test positivity rates among all ages in the intervention area and comparison area, 2016-2018. Solid line represents the line of best fit for the intervention area while the dotted line represents the line of best fit for the comparison area. The lines are plotted on a logarithmic scale. Solid circles mark the data points for the intervention area while the open squares marked the data points for the comparison area. The regression coefficient for the intervention area was $y=-13.6 \ln (x)+55.536$ and $y=$ $-0.566 \ln (x)+19.688$ for the comparison area 